\title{
LA CIUDAD COLOMBIANA EN EL SIGLO XIX
}

Adriana Paulina Giraldo M*.

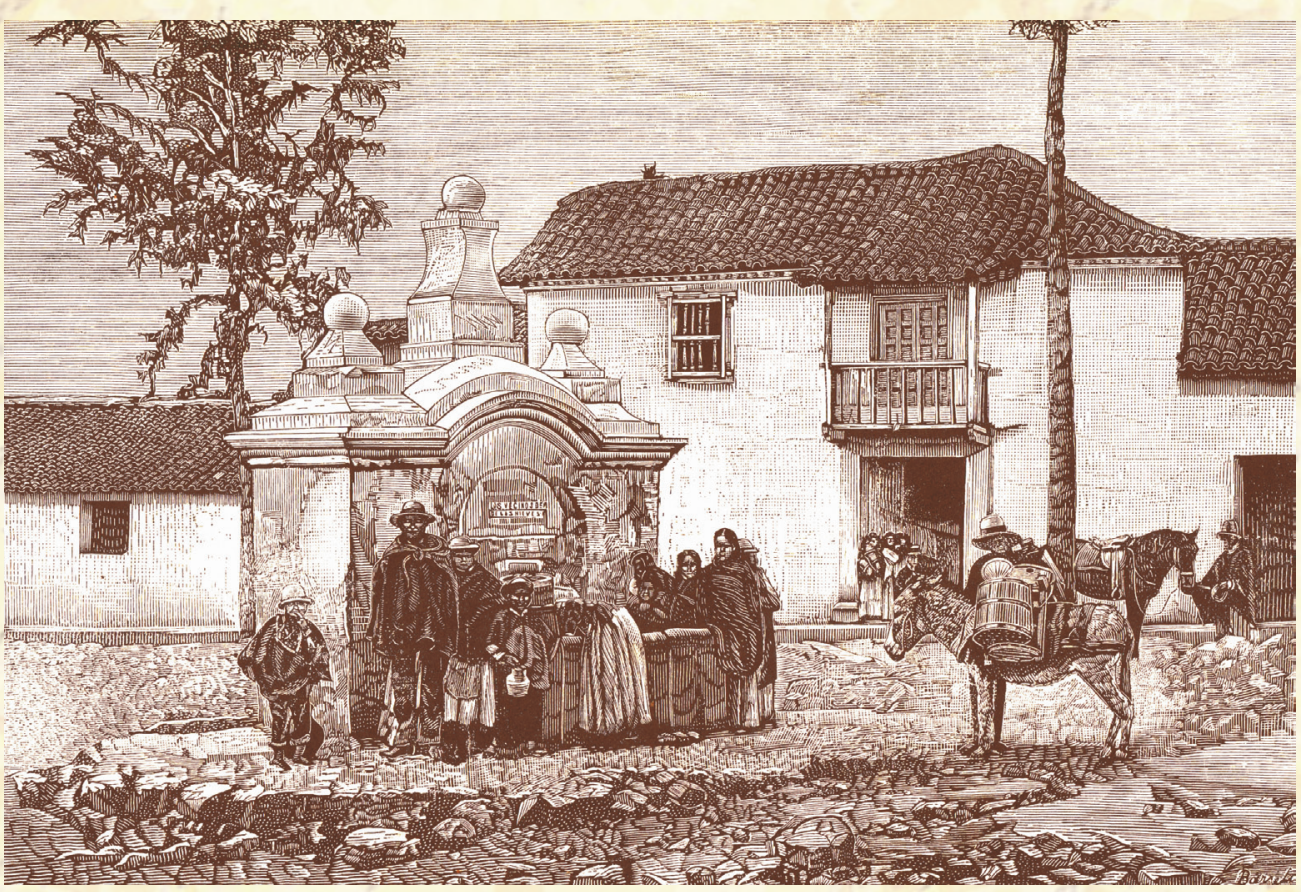

Santafé de Bogotá, Pila y Antiguo Cabildo en la Plazuela de Las Nieves, Fotografía de Racines, Grabado por Barreto. Tomado de: Papel Periódico Ilustrado Año III, Tomo III, No. 57, 1883-84, p. 140.

\section{RESUMEN}

La sociedad colombiana del siglo XIX está enmarcada bajo una continua transformación debido a su crecimiento, pero el cambio más radical sucede en la mentalidad donde se construye un ideario que cambia y transforma los conceptos de vida y, por ende, de ciudad; esta nueva ciudad donde priman nuevos valores será la génesis de las ciudades de la modernidad, es una puesta en escena de un nuevo modelo socio-económico, es una construcción y deconstrucción, es la construcción de ciudad bajo un nuevo discurso, es la construcción de nuevos modelos entre grupos que tenían repertorios diferentes, con el fin de llegar a acuerdos que se constituirán en norma.

\section{PALABRAS CLAVE}

ciudad colombiana, siglo XIX 


\section{COLOMBIAN CITY IN XIX CENTURY}

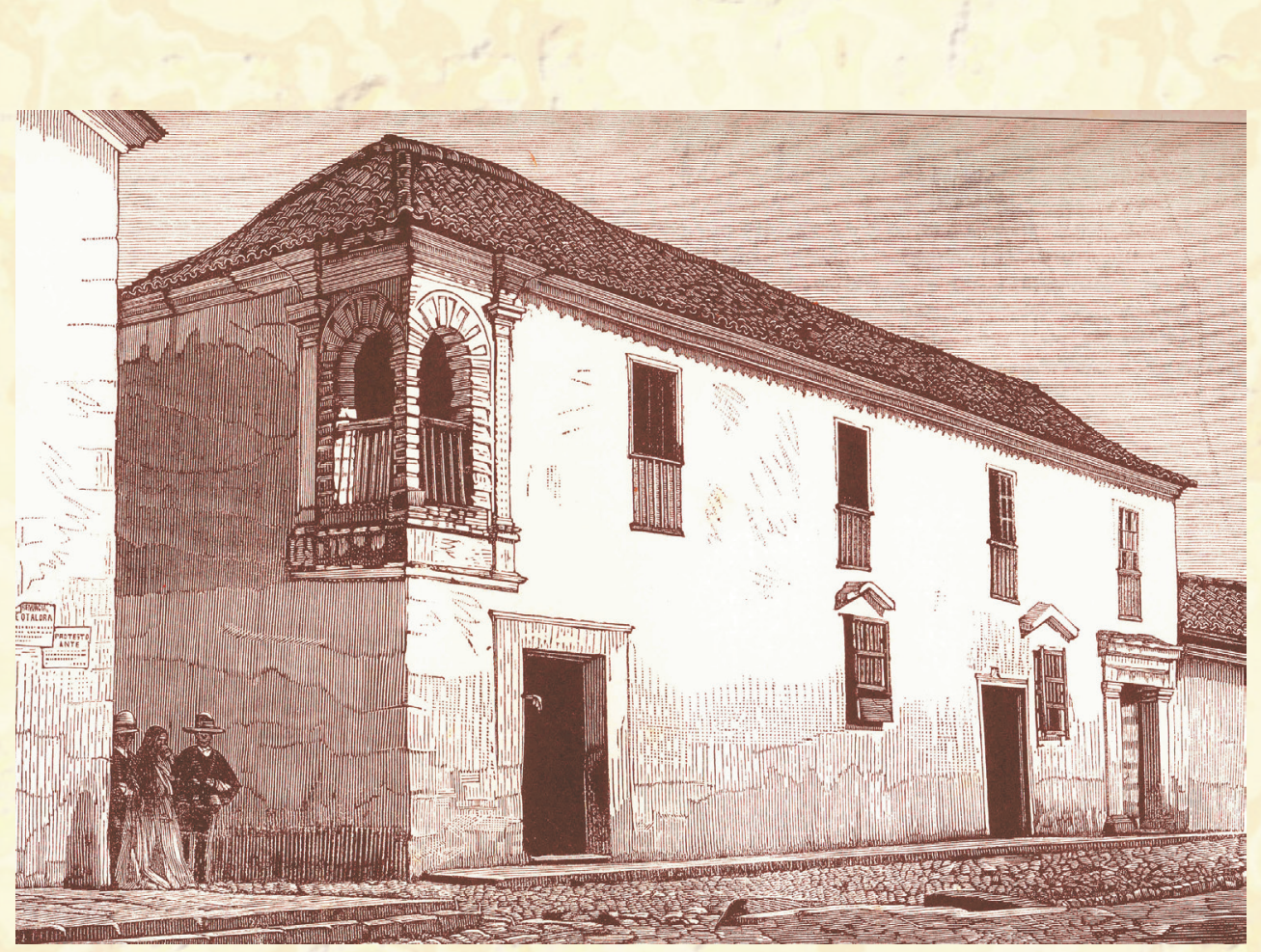

Santafé de Bogotá, Casa llamada de los Vireyes, Esquina de Las Nieves, Fotografía de Racines, Grabado por Barreto. Tomado de: Papel Periódico Ilustrado Año III, Tomo III, No. 57, 1883-84, p. 141.
Arquitecto de la Universidad Católica de Colombia, Bogotá. Especialista en Restauración y Conservación de Patrimonio Arquitectónico de la Universidad la Gran Colombia, aspirante a Magíster en Historia de la U.P.T.C. de Tunja.

Docente en las universidades Católica de Bogotá, Uniboyacá, U.P.T.C. y Santo Tomás seccional Tunja

\section{ABSTRACT}

Colombian 19th century society is framed under a continuous transformation due to its growth, but more radical change happens in mentality builds an ideology that changes and transforms the concepts of life and hence city, this new city take precedence where new values will be the genesis of the cities of modernity, is a scene of a new model implementation economic partner, is a construction and deconstruction, it is the construction of city under a new discourse is the construction of new models between groups that had different codes with.

\section{KEY WORDS}

Colombian city, XIX century 


\section{INTRODUCCIÓN}

Mientras Francia luchaba por posicionarse como símbolo mundial dentro del contexto político, económico y social, Luis XIV su rey, ostentaba su poder a partir del Palacio de Versalles, ejemplo arquitectónico de fuerza, al exterior. Desde ese poder el pueblo buscaba mejorar y hacer parte integral del mismo. España continuaba su proceso de colonización mediante la fundación y desarrollo de núcleos urbanos, según una política explícita como lo eran las reformas borbónicas, pieza fundamental del engranaje del Imperio Español. La intervención reglamentada de la corona mediante leyes constituye sin duda un programa de intervención territorial, el pueblo cumple un papel de sometimiento del territorio; los términos de la ciudad, señalados a la fundación, determinan la jurisdicción sobre un territorio, se identifican así los privilegios de la ciudad base de esta nueva forma de poder urbano. La Nueva Granada imperante como símbolo urbano territorial trae nuevos modelos de crecimiento urbano con elementos y arquitecturas que harán cambiar la imagen de ciudad. Es Versalles un ejemplo de poder y la nueva Granada otro ejemplo de poder. Aparecen personajes que tendrán influencia en estos cambios de orden, para los franceses su revolución, para la Nueva Granada el grito de Independencia, sin embargo, los testigos mudos son las grandes realizaciones arquitectónicas que aunque en diferentes lugares y tiempos marcan la imagen del mundo, la ciudad y la sociedad.

"Las voces políticas e intelectuales, relativas al papel de la ciudad como eje civilizador de la Nación ó como motor que distanciará de la mejor manera la república progresista del retraso colonial" I

Redescubrir el siglo XIX Colombiano es uno de los grandes retos de la historiografía moderna entender la dinámica de la sociedad, su conformación, su redefinición desde el orden social. El siglo XVIII poseía una estructura básica de orden y dinámica colonial y el siglo XIX será la ruptura de dicho orden, esta nueva forma de percibir ese ser social, esa construcción de sujetos y sociedades diferentes.

\section{ANTECEDENTES}

The Hispanic American Historical Review, ha sido el medio a través del cual se han publicado trabajos sobre América Latina y solamente hasta 1918 se escribió un artículo sobre Colombia: "Bolívar and the United States" (Bolívar y los Estados Unidos) estaba aún muy álgido el tema del Canal de Panamá, esta historia narrada de los héroes olvida por completo el escenario: La Ciudad. Así, se siguen publicando artículos con diversos énfasis: El transporte (1943) Tomás Cipriano de Mosquera (1950). De forma esporádica aparecerán artículos: 1972, 1984, 1985, con diversas temáticas como el trabajo de Anthony McFarlane sobre la Violencia en Colombia: Desórdenes Civiles y Populares. Otros historiadores Ingleses han estudiado a América Latina como John Lynch con sus trabajos sobre Bolívar y los Caudillos. Es la versión Eurocéntrica de nuestra cultura. Desde otra óptica más americana se destaca el trabajo de Adriana María Alzate sobre la ciudad, en el campo de la Arquitectura sobresalen Alberto Corradine, Silvia Arango con Historia de la Arquitectura en Colombia, Alberto Saldarriaga, Jorge Orlando Melo: Historia de Colombia entre otros. Germán Colmenares que estudia la Economía y Sociedad Coloniales. La conexión entre sociedad y ciudad tiene un amplio espectro de posibilidades. La conexión entre sociedad y arquitectura es una respuesta para evaluar y estudiar, los ámbitos son múltiples. 


\section{LA CIUDAD}

La llegada de los españoles al suelo americano implica transformaciones, que van implícitas desde el momento de la conquista. A mediados del siglo XVIII se empieza a consolidar la situación económica del Nuevo Reino: hay un importante repunte de la minería, el aumento de la población, el comercio de esclavos, el comercio ínter colonial, la inevitable crisis de las encomiendas consecuencia de las nuevas formas de aproximación económica, la creación de haciendas que van a surgir de la transformación de las encomiendas, -suprimidas definitivamente en 1718- estas haciendas se constituirán en incipientes ciudades, todo esto movilizará capitales que llegarán a controlar grandes capitales y formar empresas.

En el siglo XVIII la Nueva Granada tenía una demografía dispersa que estaba organizada en grandes unidades administrativas con inmensos territorios, y tenían jerarquías urbanas conformadas por Ciudades, Villas, Parroquias, Pueblos de indios y Lugares²; la organización de los aspectos urbanos sólo se da en dos ciudades: Bogotá y Cartagena que se enmarcan como los centros, uno decisorio y el otro puerta de entrada al país, donde el aumento demográfico fue considerable desde mediados del siglo XVIII hasta comienzos del siglo XIX, entre 1778 y 1800 la población aumentó un 34.13\%, pasó de 16.002 a 21.464 habitantes.

TABLA I. Evolución de la Población de Santafé (1778-1800)

\begin{tabular}{|c|c|}
\hline AÑO & HABITANTES \\
\hline 1778 & 16.002 \\
\hline 1779 & 16.420 \\
\hline 1793 & 18.174 \\
\hline 1800 & 21.464 \\
\hline
\end{tabular}

Fuente: Julián Vargas Lesmes, "Santafé a la luz de sus padrones (1778-1806), en: La Sociedad de Santafé Colonial, Bogotá, CINEP. 1990 .pp.12-13

Por ello es indispensable asumir cómo estos crecimientos van a requerir cambios desde lo administrativo, lo económico y espacial impronta que se notará en la ciudad, un nuevo direccionamiento y aparece una nueva imagen de ciudad; por ello, van a surgir numerosas disposiciones urbanas, que trabajan en dos áreas, por una parte las obras públicas, las canalizaciones, el aseo de las calles y plazas y el desplazamiento de los cementerios y otra con postulados sobre el orden social, control de la pobreza y mendicidad, por lo tanto, funciones morales y civiles ${ }^{3}$

"Durante el siglo XVIII nace una nueva reflexión sobre la ciudad, que se alimenta de diversas corrientes de pensamiento, como el poblacionismo, el mercantilismo y la fisiocracia" ${ }^{4}$

Surge el siglo XIX con unos fenómenos nuevos: El caudillismo, la región, el nuevo orden político, el partidismo, el ahorro, el sistema de crédito, la sociabilidad política, total: un periodo de transición.

El espacio urbano es el contexto natural de la arquitectura, en América el apasionamiento se dará de dos formas: el reconocimiento del espacio público como un lugar en sí y como

2 Zambrano, Fabio, "Las ciudades, clave de la dominación española, en : La ciudad plataforma de la conquista. Crónicas del Nuevo Mundo, Núm. 19. Medellín Cinep. Pág. 57

3 Alzate Echeverri, Adriana María, Suciedad y Orden. Pág.46

4 Ibídem, Pág 33 
5 Crónica de José María Caballero en: Boletín de Historia y Antigüedades No. 119 y 120 Septiembre de 1916

6 En lo relativo a la imagen de ciudad hay un doble cambio, en primer lugar. el desplazamiento del razonamiento descriptivo en términos de superioridad y de privilegio, al razonamiento en términos de rol y función; el espacio se organiza en relación con las actividades ejercidas y no en relación con el status. En segundo lugar, en el reconocimiento de la inestabilidad, lo que cuenta es la variación. Daniel Roche, La France des Lumieres, París, Fayard. 1993. Pag. 69

7 Alzate Echeverri, Adriana María. Suciedad y Orden, Pág. 35 consecuencia de lo anterior: la desinteriorización de la arquitectura, los edificios como paredes limítrofes del espacio exterior y, en segundo lugar, para delimitar los espacios internos, esa transformación fue fundamental para entender cómo la ciudad debe ser un contenedor y debe ser un telón amable para la vida. El espacio urbano es ahora un escenario, imagen que surge a través de crónicas, sabemos acerca de las construcciones transitorias como las utilizadas para las corridas de toros. A raíz de la proclamación de Fernando VII como Rey de España en 1808 se hicieron festejos en varias ciudades, el arreglo de los tablados y balcones de Honda se conservan en dibujos que reposan en el Archivo de Sevilla en ella aparecían tallados en madera Los Continentes, La Madre Patria, El descubrimiento de América.

No existen dibujos de los Arcos Triunfales con que eran recibidos los visitantes ilustres, como la llegada de cada Virrey que era una gran parafernalia. En 1816 para la llegada de Morillo, la capital estaba presidida por 30 arcos triunfales que iban desde la Plaza de San Diego hasta la Plaza Mayor, algunos eran de laurel, otros de flores, otros pintados sobre cartón, los más elaborados estaban en la plaza. De los balcones de las casas pendían banderitas y cortinas de damasco; además se hicieron carros con comparsas y cabalgatas ${ }^{5}$

Hacia finales del siglo XVIII y comienzos del Siglo XIX la corona se esfuerza por construir edificios de carácter civil, los intereses se transforman, van a surgir: Cabildos, Casas de la Moneda, Aduanas, Correos, Hospitales, Cementerios, Fábricas de Aguardiente, Cárcel. La costumbre se mezclaba con usos como la vivienda, transformaciones ya no tan sutiles del espacio público que es el verdadero contenedor.

¿Dónde se producen los cambios? En la exteriorización de las ideas, es el debate desde la plaza, la calle, la chichería, en el atrio de la Iglesia, que se constituye en punto de encuentro, es la ciudad la que maneja un nuevo discurso del espacio público, es el lugar donde los grupos no oficiales airean sus ideas, es un lugar de agitación, encuentros y desencuentros.

\section{CALLE BOGOTANA SIGLO XIX}

La ciudad se vuelve el centro regulador donde todo converge, lo económico, lo político, lo cultural. Esta nueva forma de pensar transforma y favorece las evoluciones internas que van en el ordenamiento del espacio, en los vínculos sociales y culturales ${ }^{6}$ Lo que se gesta es la génesis de la "ciudad moderna". Los ideales de la ilustración exigen la adecuación de los espacios urbanos y sus funciones: militar, comercial, política, residencial y religiosa.

\section{Imagen I: Bogotá, Calles $2^{\mathrm{a}}$ y $\mathrm{I}^{\mathrm{a}}$ de Florian (Carrera $\mathrm{I}^{\mathrm{a}}$ al occidente)}

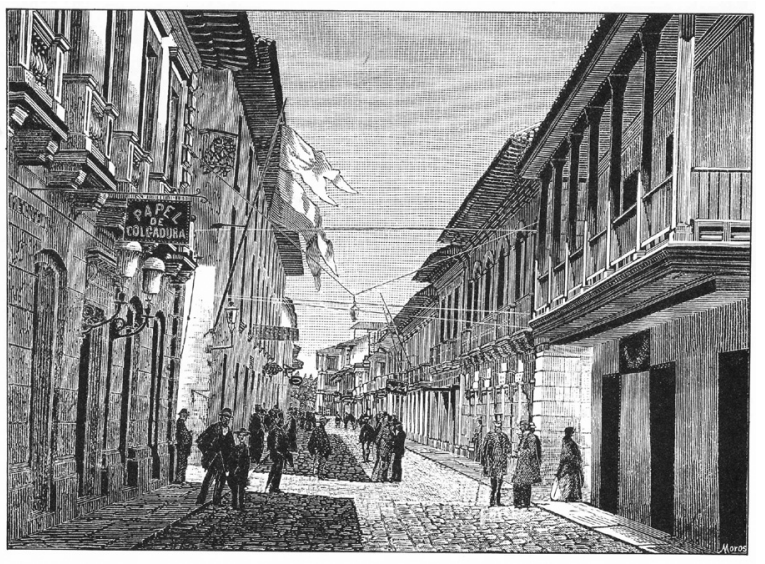

Fuente: Papel periódico ilustrado Año III, Tomo III, No 64, 1883 - 1884, 1․ 252. 
Uno de los aspectos importantes de esta nueva concepción es el uso del término "Función" que servirá para tratar y estudiar sus problemas, este término usado en el campo económico y médico se hace análogo a la ciudad como un organismo vivo: "su corazón y arterias palpitan" la ciudad es un "vientre que asimila los alimentos y excreta la basura"

La apariencia de las ciudades fue muy diversa, pues debe reflejar esta sociedad multirracial y con diferentes niveles de ingresos, esta apariencia debe reflejar las estructuras sociales dentro de las que se halla la estructura eclesiástica. Cada sector de la ciudad deberá entonces reflejar sus características cuantitativas y cualitativas.

\section{Imagen 2: Vendedora de carne}

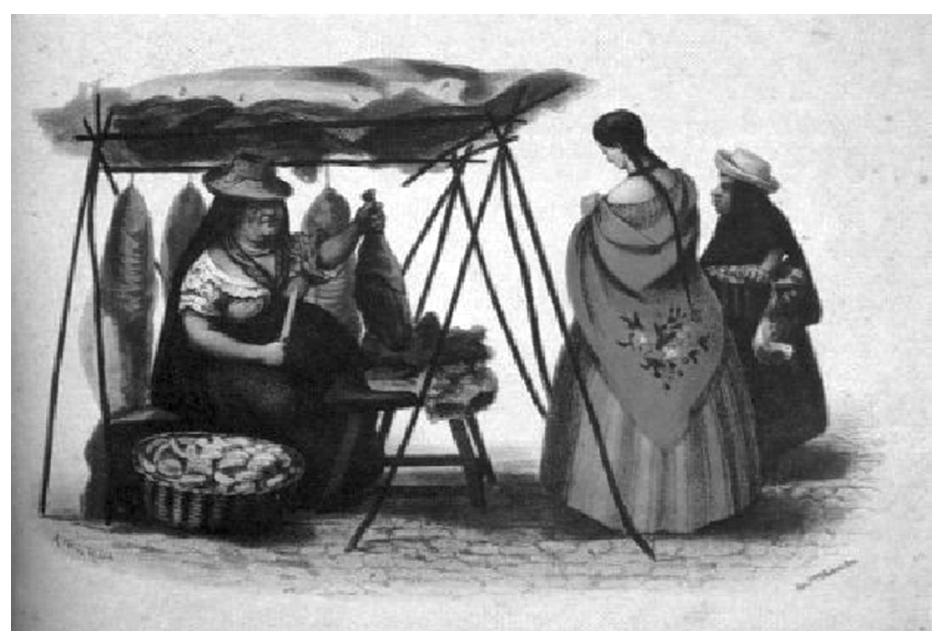

Fuente: www.historiacocina.com

La ciudad colonial era el escenario donde todo se mezclaba, las categorías étnicas y sociales, donde la vida, con sus múltiples rituales, se construye con el tiempo. Las disposiciones de la corona pusieron en evidencia desde el comienzo su preocupación por lo estético y la exigencia de salud pública y moral, ellas revelan la necesidad de disciplinar la sociedad por medio de la ciudad, el ordenamiento de la ciudad revela cómo debían ser los patrones de conducta, todo aquello que contravenía esta normatividad se hallaba extramuros como sucedía con la vivienda dispersa indígena, incluso no representaba gráficamente en los planos de ciudad éstos "no existían".

Hay intentos por controlar el espacio y sus usos, se trataba de regulaciones que abarcaban iluminación, aseo, empedrado, pero, a pesar de las disposiciones, casi nunca se cumplían pues aunque había alcaldes, regidores, comisarios de barrios y alguaciles era necesario avivarlos, sostenerlos y forzarlos constantemente a cumplir sus labores ${ }^{8}$

Sólo hasta finales del siglo XVIII comienza el fortalecimiento fiscal debido en gran parte a los préstamos que los cabildos hacían a los particulares, por ejemplo, de los 5.590 pesos recogidos por el cabildo en 1785 se originaron en los ejidos: es decir, provenían del arrendamiento de sus propiedades inmobiliarias urbanas y rurales: lotes, solares, casas bajas, tiendas y potreros entre otros.

8 Ver quejas del gobernador de la provincia de Antioquia por el estado de la policía de toda la provincia y la negligencia y desobediencia ante lo ordenado por las autoridades (AHA, Colonia, Fondo de documentos. Tomo 6I0) en : AHA, Fondo Minas, Doc. II 242 Folio I. 


\section{Imagen 3: PLANO DE BOGOTÁ 1810}

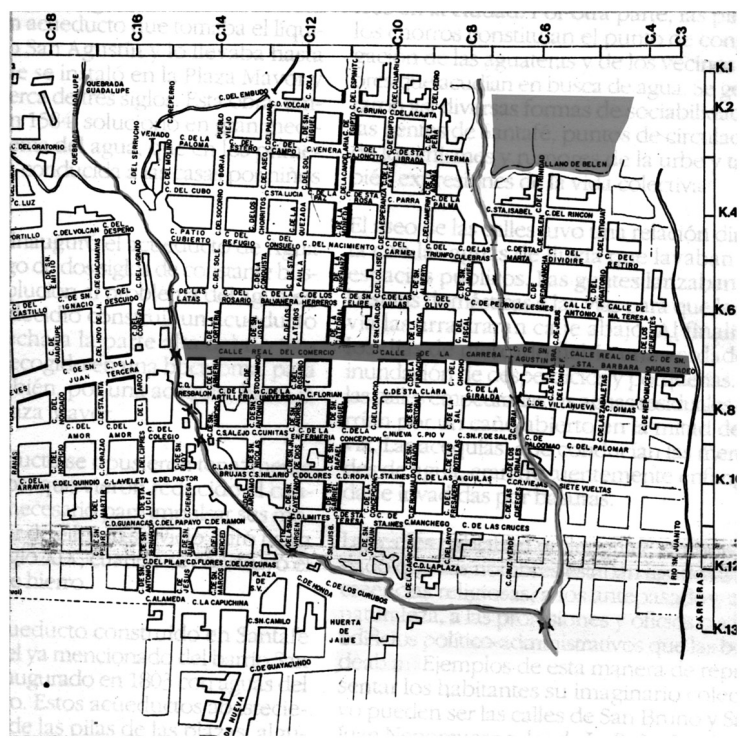

Fuente: Gutiérrez Ramón, et. al. "Fray Domingo de Petrés y su obra Arquitectónica", Banco de la República/El Áncora Editores, 1999

Tabla 2: Ingresos del Cabildo de Santafé (1735 - 1796)

\begin{tabular}{|c|c|c|c|}
\hline AÑO & INGRESOS EN PESOS & GASTOS EN PESOS & CRECIMIENTO ANUAL \\
\hline 1735 & 2.274 & 2.294 & $1.4 \%$ \\
\hline 1785 & 5.590 & 5.196 & $2.9 \%$ \\
\hline 1796 & 6.859 & SIN DATOS & $2.0 \%$ \\
\hline
\end{tabular}

Fuente: Julián Vargas Lesmes, "El muy ilustre Cabildo de Santafé, Finanzas y administración económica, en: Julián Vargas (Ed.). La Sociedad de Santafé Colonial, Bogotá, Cinep. 1990

Estas fuentes adicionales de recursos en concurso con el sistema de impuestos afecta entonces la forma y estructura urbana, un nuevo modelo llegará: la visibilidad en lo urbano, que rompe los esquemas y afecta las dimensiones sicológicas, la ciudad da muestras de civilización: la iluminación urbana, mientras los europeos utilizaban sofisticadas lámparas de petróleo, en Colombia se instaura un sistema arcaico de iluminación; es el deseo de un nuevo aspecto urbano que condensa las exigencias de seguridad, moralidad y orden público, el alumbrado "marca" la temporalidad de la calle a pesar de ser rudimentario: con faroles, con velas de sebo, y/o con teas (astilla de madera resinosa). En I 794 el Cabildo de Santafé designó 3.000 velas al año para el alumbrado de ciudad, en I.804 gastaron 10.248 velas que costaron 3.200 pesos para iluminar una ciudad de aproximadamente 21.000 habitantes ${ }^{9}$, pero a pesar de ello, considerado el tamaño de la ciudad el servicio debió ser precario. El Virrey Amar da disposiciones relativas al alumbrado de Chicherías y Pulperías en el auto publicado el 16 de abril de I804, la vigilancia del cumplimiento de la protección del espacio público quedaba en manos de los alcaldes de barrio. No obstante, la luz pública no mejora substancialmente hasta el siglo XIX. En el reglamento dictado en Cartagena en 1789 se destaca: los pulperos y taberneros están obligados a poner durante las noches: "farolas bien condicionadas con luces sobre sus puertas hasta las nueve de la noche" y los que "tuvieren sus pulperías y tabernas en las esquinas deberán colocar dichos faroles de modo que puedan alumbrar las cuatro cuadras" 10 
De igual forma en los núcleos coloniales, la distribución del agua constituyó a menudo un indicador de las divisiones sociales, espaciales y económicas. En Santafé muy pocas casas tenían aljibe propio, sólo las familias más distinguidas o comunidades religiosas contaban con "mercedes de agua". Santafé, a pesar de hallarse inmersa en un contexto con fuentes hídricas, no poseía acueducto y la ciudad se surtía de diversas fuentes: una en la Plaza mayor, otras en San Francisco, Las Nieves y San Victorino que se ubicaban en las plazas y plazuelas de la ciudad, allí también se generan cambios, la ciudad carece de alcantarillado y sus fuentes hídricas se contaminan con toda clase de desechos, se halla la necesidad de canalizar las aguas para evacuar y drenar todos los desechos, por cuanto estos se constituyen en fuentes de propagación de numerosas enfermedades.

La visión idílica de la ciudad neogranadina es irreal, durante casi toda la época colonial los acueductos se reventaban y las acequias se hallaban llenas de basura, al deslizarse abrían canalones, producían barrancos e inundaban las calles, la canalización de los ríos que dividían la ciudad, transformará para siempre la imagen de la misma. En efecto el rediseño de la ciudad es una realidad que se debe afrontar, las ordenanzas de infraestructura se continuarán promulgando a lo largo del siglo XIX.

La iglesia con su impronta cultural y social marca la diferencia, es esta institución la primera en dar un giro, una transformación de ciudad, al traer un nuevo lenguaje. Es la Iglesia la que posee un lugar estratégico en la ciudad. La ciudad en la Nueva Granada se caracteriza por la universalidad del modelo en damero, donde las élites poseen los espacios privilegiados de la ciudad: cuando se gesta la organización social de la ciudad la Iglesia aparece siempre en contexto de la plaza, y, en la medida que se alejan de este espacio, se determina su importancia dentro de la ciudad, de la misma forma se diferencian en volumen y estilo; los materiales de construcción varían de acuerdo a los ingresos, así la ciudad posee diferenciación cuantitativa y cualitativa de materiales de construcción, las técnicas son una mezcla de lo vernáculo y el modelo español, la ciudad está conformada por parroquias, es la Iglesia el eje del tejido urbano y en su interior las decoraciones barrocas plasman la mentalidad católica.

\section{LA INDEPENDENCIA}

El siglo XIX fue una transición lenta y dolorosa ya que pone en escena dos grandes propósitos nacionales: la Independencia y la puesta en marcha de la República Liberal Democrática.

Los levantamientos revolucionarios y las respuestas represivas de la corona constituirán el desafío, sobre el modo de la respuesta y entre las que se hallaron fue esta forma de intervenir en la ciudad y el territorio que va a reflejar la construcción de un nuevo ideario; otra forma de aproximación es la propuesta en escena de un nuevo modelo socioeconómico que se desprende de un nuevo modelo sociocultural. Pero estas propuestas requieren escenarios, son transiciones lentas $y$, a veces, con contramarchas que tienen instrumentos que permiten su desarrollo.

La Guerra de Independencia tiene costos muy elevados no sólo como pérdida de vidas sino en términos económicos, con una gran masa poblacional rural, una economía minera empobrecida; con la guerra la economía de las haciendas se deteriora, los ejércitos consumen gran parte del ganado, los caudillos tienen la gigantesca tarea de reorganizar el fisco y establecer una estructura jurídica que se verá a través de varias administraciones que van desde 1830 hasta 1850: gobiernan en ese lapso Santander, Herrán y Mosquera, se suprime el estanco del tabaco, la reducción de los impuestos de aduana, la desamortización 
de manos muertas; el desangre continúa debido a las guerras internas, los problemas neogranadinos eran muy complejos pues la falta de mano de obra, la escasa agricultura y el auge del contrabando, generaron precios bajos y empobrecimiento del comercio, además, el fraude fiscal. En estas circunstancias hubo muy poco dinero para construir, por otro lado, las ciudades colombianas permanecieron estáticas o disminuyeron de población como en el caso de Cartagena que en I834 tenía 22. I7I habitantes y en I.88I solo 9.86 I, se suceden fenómenos de migración hacia Panamá, Popayán, Santafé de Antioquia, Tunja o Mompox, apenas subsistieron.

La dependencia de una economía primaria, basada en la agricultura y la minería que ven caer su estructura al perder a su socio comercial que era España, anudado a esto están los conflictos regionales. Por ello, los nuevos gobiernos deberán afrontar la deuda externa acumulada por la Independencia que se gestó en la necesidad luchar y equipar al ejército. ¿La fórmula? Aumentar los impuestos, aunado a la perpetuación de sistemas de valores y jerarquización social donde la perpetuación de la élite orienta la economía hacia la agricultura la creación de países separados disminuyó el intercambio comercial, era una economía incipiente inmóvil con un comercio interno para satisfacer.

La movilidad social era un hecho en el siglo XVIII y XIX, para los nuevos gobiernos el ascenso de los criollos romperá la brecha de las rígidas líneas sociales, hecho que la ciudad mostrará al transformar su estructura social, la carencia de restricciones hará surgir que las nuevas repúblicas terminen con grandes formaciones militares que era una forma de ascenso social. Sin embargo, no todos los grupos humanos que conforman estos nacientes estados lograron inclusión, la ausencia de los negros e indios que incluso pierden privilegios ganados con la corona, eran los mestizos los que estaban en la centralización del poder, y hay grupos como las comunidades religiosas que se fortalecen a través de estas nuevas naciones.

Esta construcción y deconstrucción de ciudad es la relación natural entre la forma urbana y su uso, la ciudad crece y con ella su vitalidad y funciones alternativas, esta es la base de la construcción de un nuevo ideario que cambia lentamente las estructuras sociales, es la ciudad y su crecimiento la herramienta visible de los cambios, es una campaña anti-española en la arquitectura y las artes decorativas, rotos los esquemas sociales tradicionales. ¿Por qué no una arquitectura que responda a estos cambios? Así, la construcción es producto no sólo de híbridos culturales, sería mejor la construcción de acuerdos entre grupos que pedían repertorios diferentes, con el fin de llegar a un acuerdo que se constituirá en norma. Por otro lado, se halla la invitación del pensamiento ilustrado donde la coerción no es la mejor respuesta, se busca la "opinión del Experto" o individuo más representativo como lo observamos en la disposición de proyectos entregados a personas que poseen experiencia y conocimiento determinado, "experto" que era designado por las autoridades, ya no se solicita a la autorización de la Academia de San Fernando para la toma de decisiones, ahora el experto: justifica y legitima; desde un punto de vista la ley se funda en el saber, está desprovista de intereses políticos y se funda en su utilidad, es una perspectiva neutra como lo fue el caso de Petrés o Esquiani. Uno era sacerdote y el otro militar. Precisamente en las condiciones mencionadas las obras arquitectónicas de cierta envergadura buscan expresar los sentimientos colectivos por ello su expresión más pura será la construcción del Capitolio Nacional, con Tomás Reed es, sin lugar a dudas, la obra más ambiciosa y simbólica del siglo XIX, el siglo comienza con la Catedral de Bogotá de Petrés y finaliza con la obra del Capitolio que representaba la construcción misma de la Nación. El Capitolio tal como lo soñara Mosquera y Reed tardaría más de 80 años en su construcción demuestra con su historia los avatares de la patria, la inestabilidad política, la pobreza estatal, la carencia de diseñadores. 
Los procesos de culturización, recepción, normatividad e imagen como dinámica cultural engendran movimientos a veces contradictorios. En la circulación de material cultural de cualquier sociedad hay desplazamientos y transporte, se franquea una distanciall

En la selección hay un punto de partida con estos valores culturales, en el punto de llegada hay reinserción, adaptación, mediación, contextualización. Es la mentalidad la que va a transformar el camino para hallar los puntos de encuentro y de partida de un conjunto de ideas que son la base de la ciudad moderna.

\section{CONCLUSIONES}

La modernidad como elemento de cambio, muestra cómo la sociedad y la imagen de la ciudad cambiaron y dieron una nueva identidad social y cultural, el panorama político enmarca un renacer hacia la creación y estructuración del concepto de país.

El surgimiento de un sentimiento americano en el siglo $\mathrm{XIX}$ se ve reflejado en la ciudad, que se transforma en el escenario, donde hay un reconocimiento del espacio público, objeto fundamental ahora del contexto urbano, el marco de referencia americano-español es el contexto natural en el que se desenvuelve la arquitectura neogranadina, la organización espacial va a representar la movilidad social, lo multiétnico y lo multirracial, aparecen los necesarios usos públicos, el rediseño de ciudad es una realidad, la impronta la darán las obras representativas, los procesos de recepción, la normatividad y la imagen sobresalen como factores definitorios en el proceso de construcción de nación.

\section{BIBLIOGRAFÍA}

ALZATE ECHEVERRI, Adriana María. “Suciedad y Orden”. Universidad del Rosario, Bogotá, 2002

ARANGO, Silvia. “Historia de la Arquitectura Colombiana”. Universidad Nacional, Bogotá, 1988

CHARTIER, Roger. Los orígenes de la Revolución Francesa. Seuil, París, I99।

Mejía Pavony. Et al. “Colombia en el Siglo XIX”. Planeta, Bogotá, 1999

MORA DE TOVAR, Gilma. "Chicha, Guarapo y presión fiscal en la sociedad colonial del siglo XVIII”. Bogotá, I 980

ROCHE, Daniel. «La France des Lumieres ». Fayard, París, I 993

SOLER, Luisa Consuelo."El Reformismo Borbónico en América, el Caso de la Nueva Granada siglo XVIII". UPTC, 2005

VARGAS LESMES, Julián; ZAMBRANO, Fabio. “Evolución Histórica de los servicios públicos” en: Bogotá 450 años Retos y Realidades, Bogotá, IFEA, 1988

ZAMBRANO, Fabio, “Las ciudades, clave de la dominación española, en: La ciudad plataforma de la conquista. Crónicas del Nuevo Mundo, Núm. 19. Medellín Cinep
II Roger Chartier, Los orígenes de la Revolución Francesa, París, Seuil, I.99I, pág. 30-31 